\title{
Research on Economic Rationality of the Emergence of Industry Association
}

\author{
Feng Xiao \\ Sichuan Technology and Business University \\ Chengdu, China 611745
}

\begin{abstract}
Industry association is an ancient and important mechanism of economy governance and indispensable organization in market economic system. In this article, it respectively elucidates the economic rationalities of industry association's internal cost saving and external competitive cooperation, from the two key perspectives of economic theories of transaction costs theory and modern game theory, so as to deeply disclose the internal logic of the emergence of industry association.
\end{abstract}

Keywords-industry association; economic rationality; transaction costs theory; modern game theory

\section{INTRODUCTION}

"Rationality" has been an important subject of western philosophy for about thousands of years, and since modern times, a group of famous ideologists represented by Weber and Habermas have conducted deep research on it, however, there are still lots of disputes existing in educational circles so far. The author thinks that, "rationality" mainly refers to the degree of meeting people demands and logic harmony of the continuously emerging new things in the development process of human society. Therefore, for researching the economic rationality issues of the emergence of industry association, the author will conduct analysis in following two terms: one is the internal motivation factors of the emergence of industry association, e.g. the internal subjective desire the industry association relying on - pursuit to transaction cost saving; the other one is the external condition of the emergence of industry association, e.g. the external means of enterprise the industry association relying on - accomplished by means of cooperation and competition game. Therefore, the rationality of the emergence of industry association is mainly from the internal demand of enterprises to realize transaction cost saving by means of externalized cooperation and competition game.

\section{INTERNAL MOTIVATION FACTORS OF THE EMERGENCE OF INDUSTRY ASSOCIATION: FROM THE PERSPECTIVE OF TRANSACTION COSTS THEORY ${ }^{1}$}

The conception of transaction costs was firstly put forward by Coase, an economist of USA, in The Nature of the Firm in 1937. Coase indicates that transaction is the "cost using price

${ }^{1}$ The contents of this section mainly refer to the related research result of Qin Shili. mechanism", however, many experts and scholars have different explanations on it. Actually, transaction costs is a conception relative to production costs, the former reflects the relationship of "people - people" and the latter reflects the relationship of "people - object". Essentially, as long as exchange activities exist in human society, transaction costs will exist. Hence, the transaction costs theory initially taken to analyze the enterprise logic essence now is widely applied to researching various social economic systems.

Industry association, as a mechanism of economy governance, is a medium mechanism between market mechanism and non-market mechanism. The existing of industry association is to make up the defect of the both, in other words, is to reduce transaction costs for obtaining higher economic efficiency. Concretely, the defect of market mechanism is shown as market failure, while the defect of non-market mechanism mainly is shown as government failure

The market failure theory emerged with the birth of Keynesianism and successful implementation of Roosevelt's New Deal after world economic crises breaking out in 1930s. Market failures recognized in economic circles mainly include monopoly, negative externality and lack of public goods provision. ${ }^{2}$ However, different scholars have their own emphasis analysis on the causes of market failures. Paul Sanmuelson thinks that, the key factor causing market defect is the imperfect competition of market, hence, emphasize the signification of government conducting control and antimonopoly aiming at public industries, so as to make up the defects of market. ${ }^{3}$ And Daniel Spullber thinks that adverse selection, moral hazard and information asymmetry are the root reasons causing market failure and the government shall take proper control measures. And Charles Wolf thinks that the externality of market organizational behavior is the root point causing market failure.

The author relatively agrees with Wolf. According to Wolf's perspective, market organizations all take actions under the principle of own maximum interests (or own minimum interests). Under conditions without special constraint, the market organization will not take the earnings of other

\footnotetext{
${ }^{2}$ Sun Lijun. Institutional Logic of Industry Association [D] Shanghai: Fudan University Press, 2003.

3 Qin Shili. Nature of Chamber of Commerce: A Research from the Perspective of Market Failures and Non-market Failures [J]. Zhejiang Social Sciences, 2001 (5).
} 
economic subjects into consideration. Hence, under the condition of negative externality, the private marginal cost of market organization is lower than social marginal cost while the private marginal revenue is higher than social marginal revenue, hence, the output of market organization trends to be higher than the social requirements and vice versa.

According to this, we can take the perspective of Wolf as Assumption I: the main cause of market failure is the externality of market organizational behavior. Due to the fact that the pure market price mechanism cannot overcome own inner defect, it must be with the assistance of interruption of the external strength, and then the government becomes the optimal option. Therefore, we acquire the Assumption II: The supervision of government on market organization is fair and effective. The government, as the external strength of market, inflicts interruption on it to limit the negative externality of market for reducing transaction cost. Nevertheless, the government intervenes in market mechanism as a non-market mechanism, which will have certain influence on the market according to different degrees hereby defined as nonmarketization degree. Based on experience and general knowledge, we acquire Assumption III: the transaction costs due to market subject reduce with the increase of nonmarketization "Fig. 1".

Transaction costs caused by externality

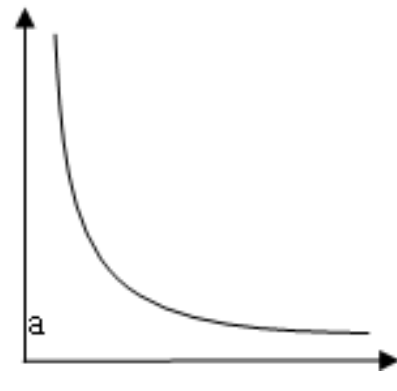

Degree of non-marketization

Fig. 1 The change of tranction cost over the degree of non-marketization

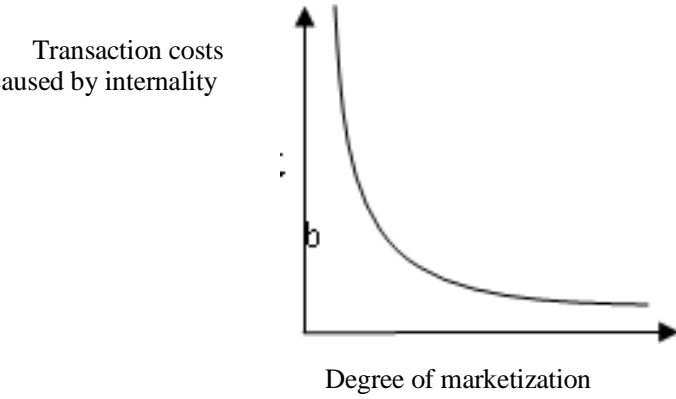

Fig. 2 The change of tranction cost over the degree of marketization

Government failure theory was born at the right moment in 1970 s based on severe "stagflation phenomenon" generally occurred in western countries. An important distinction between market mechanism and non-market mechanism is: the income of market organization is mainly from the price income of commodity transaction while the income of nonmarket organization is mainly from the non-price income of revenue and donation etc. ${ }^{4}$ Well-known theories of government failure include: public choice theory of Buchanan, theory of collective action of Olson, rational expectations theory of Lucas and theory of monetarism of Friedmann etc, which introduce the government failure phenomenon of government's self-interest tendency, bureaucratism and rentseeking phenomenon from different points of view.

Wolf thinks that the reason of government failure is lacking of a non-market mechanism which can adjust and calculate the cost and income of both the government or organization and the whole society. ${ }^{5}$ The activities of market organization all is subject to the price mechanism related to "cost - income", while the income source system of nonmarket organization breaks the normal operation of price mechanism. As we know, the principle of market organization behavior is the external price signal of its own, while lacking of thus external principle, the government organization must draw support from internal principle of its own (internality) to guide the operation of institution and personnel behavior. Therefore, the "internality" named by Wolf refers to the transaction arising from that the government may deviate from the pursuit to maximization of social effect and turns to pursue to maximization of government internal personnel effect under the condition lacking of effective external supervision (market biding mechanism) and internal supervision (democracy balance mechanism) ${ }^{6}$.

Accordingly, we can acquire Assumption IV: government failure is mainly caused by the internality of government institution. If assume democracy balance mechanism is a given perfect and high-effective mechanism, then the transaction cost due to government failure mainly subjects to the influence degree of market bidding mechanism on it (marketization degree). Therefore, we acquire Assumption V: the transaction cost caused by non-market subject reduces with the increase of marketization degree "Fig. 2".

In conclusion, we know that industry association is neither pure market organization (enterprise) nor pure non-market organization (organization). Just because industry association is thus medium mechanism, it can reduce both the transaction costs due to the externality of market organization and the internality of non-market organization, so as to obtain lower total transaction costs. (As shown in "Fig. 3", curve 3 comes from superposition of curve "a" and "b" from "Fig. 1" and "Fig. 2", referring to the total transaction cost of enterprise). The cost-saving mechanism of transaction cost reflects the essence of enterprise's profit-seeking demand, which is just the essential support of the rationality of industry association existing.

\footnotetext{
${ }^{4}$ Government organization is a main component of non-market organization, hence, make research on it as representative.

${ }^{5}$ Charles Wolf, Xie Xu (translator): Market or Government - Weigh of two imperfect options [M]. Beijing China Develop Press, 1994:138.

${ }^{6}$ Sun Lijun. Institutional Logic of Industry Association [D] Shanghai: Fudan University Press, 2003
} 


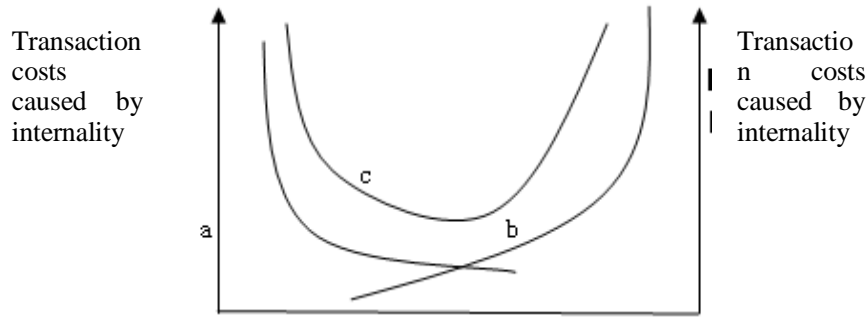

Degree of marketization

Degree of non-marketization

Fig. 3 The relationship of otal transaction costs with marketization

\section{EXTERNAL CONDITION OF THE EMERGENCE OF INDUSTRY ASSOCIATION: FROM THE PERSPECTIVE OF MODERN GAME THEORY}

Game theory, also known as "strategy theory" or "theory of game", is a mathematical theory method having belligerence or competitiveness. In 1944, Games and Economic Behavior the epoch-making magnum opus, jointly written by Von Neumann and Morgenstern, established the theory basis and method system of this subject, from then, game theory started applying to economic research field in large scale systematically.

The basic terms of game theory include: player, strategies, orders, payoffs and equilibrium etc. players are the decisionmaking main body under the principle of self-interest; strategy is a suit of action scheme for players; order refers to the sequence of players adopting actions; payoff is the function result relative to a group of strategies adopted by players; equilibrium refers to the steady state the players reaching through game.

The industry association, as an important economic system in modern social economic system, the emergence way of which mainly comes from the choice of competition and cooperation made by enterprise. When analyzing the enterprise relationship within the industry under modern industry organization, it often assumes that the behavior relationship among enterprises emerges directly, while in the practice, thus relationship often needs to pass the action mechanism of industry association. Therefore, it may be deemed that industry association is the critical point of cooperation and competition reached by enterprises through games.

In practical economic life, enterprise is restricted by the limited rationality and shackled by opportunism instead of being like the market main body assumed in classical economic model in most cases, which has complete rationality and steady preferences. Enterprise cannot know the internal and external environment very well it belonging at all; for things profitable in the exterior, the enterprise often does opportunistic things as much as possible. Hence, combining with limited rationality and opportunism will damage the fairness and effectiveness of the whole market transaction greatly, and reduce the whole operation performance of the market finally.

Therefore, we establish a simple game model to explain the internal transaction situation of the industry before and after the emergence of industry association as well as the external rational basic condition for realizing the transaction mechanism of industry mechanism. Just due to the obvious distinction before and after the emergence of industry association, it promotes the enterprise having the subjective will of establishing the mechanism of industry association. Also due to this game way, it provides the enterprise with a platform for it making choice between the two ends of competition and cooperation and finally establishes the external security for the foundation of industry association.

Firstly assume that:

\section{(1) Game players: A and B}

(2) Game strategy set: (cooperation and cheat)

(3) Assumption of game players' limited rationality and opportunism

Under the condition without external intervention, enterprise A and B, based on assumption of limited rationality and opportunism, have the game strategy set: (cooperation and cheat) in common, and accordingly, we can establish a simple payoff matrix. (see table 1), obviously, under the condition both parties choosing cooperation, both $\mathrm{A}$ and $\mathrm{B}$ can acquire maximum income $(10,10)$; while if both parties choose cheat strategy, both parties obtain minimum income $(4,4)$. Nevertheless, when B choosing cooperation, by choosing cheat strategy A will obtain maximum income, while when B choosing cheat, by choosing cheat strategy A will obtain maximum income as well, e.g. no matter how B choosing, A's optimal strategy is cheat; similarly, no matter how A choosing, B's optimal strategy is cheat as well. Therefore, we can know that the reason causing the balance result damaging everyone is that: there is no complete information communication or basic goodwill guarantee between both game players.

TABLE I. A PAYOFF MATRIX OF ENTERPRISE A AND B

\begin{tabular}{|l|l|l|}
\hline & \multicolumn{1}{|c|}{ Cheat } & Cooperation \\
\hline Cheat & $(4,4)$ & $(18,2)$ \\
\hline Cooperation & $(2,18)$ & $(10,10)$ \\
\hline
\end{tabular}

By this token, it is very hard only relying on the rationality discovery of the game players per se to get rid of the predicament of social transaction efficiency loss. Accordingly, it seems very important to introduce a brand new governance mechanism both having external restraint system and internal values, which shall make all the players adopt cooperation strategy effectively to avoid punishing and fighting for income as well as reach the balance result of win-win, even multi-win finally.

This mechanism shall be considered as a mechanism punishing breached transaction action and protecting honest transaction conception as well as the coordinator role in 
neutrality position. And this mechanism shall have two basic functions: (1) information supply function. It can improve the poor information situation among players, completely disclose information for enterprises making rational decision. (2) behavior restriction function. It can effectively stimulate honest behavior and restrain opportunistic behavior. Accordingly, industry association is thus a economic governance mechanism meeting the said conditions.

With the introduction of industry association mechanism, the original payoff matrix changes. "Table II" in the face of newly preset game rules and relative balance result, the game players will, based on the rationality, choose strategy set of (cooperation, cooperation) to reach favorable social transaction situation benefitting everyone.

TABLE II. The ChANGE OF PAYOFF MATRIX

\begin{tabular}{|l|l|l|}
\hline \multicolumn{1}{|c|}{ C } & Cheat & Cooperation \\
\hline Cheat & $(4,4)$ & $(0,2)$ \\
\hline Cooperation & $(2,0)$ & $(10,10)$ \\
\hline
\end{tabular}

Under normal condition, people may think that government acting as thus neutral coordinator role is proper. However, in the practice, due to incomplete of legal mechanism and inefficiency of democratic balance, it may cause inundation of government failure phenomenon of power rent-seeking, so as to increase transaction cost of enterprise. As a nongovernmental transaction coordination mechanism, the industry association wins general trust of enterprises because of its internal independent spirit, public state and authority power.

From the foregoing we know that, the formation process of industry association refers to the process that enterprises realize their own interest maximization through game of competition and cooperation under rational conditions. Hence, game theory is the external basic condition to promote the combination of enterprises' natural pursuit of profit and transaction convenience of industry association.

\section{CONCLUSION}

Industry association refers to a series of contract arrangement reached by each main body of market through repeated games for reduction of transaction costs, hence, industry association is a special outcome for coordinating parties' interests when the commodity economy develops to a certain degree.

\section{REFERENCES}

[1] Charles Wolf, Xie Xu (translator): Market or Government - Weigh of two imperfect options [M]. Beijing China Develop Press, 1994:138

[2] Wang Hongtao. Institutional Economics - Interpretation of Institution and Institutional Change [M]. Shanghai: Fudan University Press, 2003.
[3] Sun Lijun. Institutional Logic of Industry Association [D] Shanghai: Fudan University Press, 2003.

[4] Qin Shili. Nature of Chamber of Commerce: A Research from the Perspective of Market Failures and Non-market Failures [J]. Zhejiang Social Sciences, 2001 (5)

[5] Qin Shili, Cen Cheng. Chamber of Commerce: Interpretation from the View of Transaction Costs [J]. Shanghai Economic Review, 2002, (4). 